\title{
Design of Pelton Turbine and Bucket Surface using Non-Uniform Rational Basis Spline and its Analysis with Computational Fluid Dynamics
}

\author{
Neeraj Adhikari, Anup Pandey ${ }^{a}$, Anushka Subedi, Nitesh Subedi \\ Department of Mechanical and Aerospace Engineering, Pulchowk Campus, Institute of Engineering, Tribhuvan University, Nepal \\ Corresponding Author: a 074 bme605. anup @pcampus .edu.np
}

Received: 2020-08-25

Revised: 2021-02-06

Accepted: 2021-03-02

\begin{abstract}
:
Hydraulic turbines are used to convert the energy in flowing water to rotational mechanical energy. The design of high head Pelton turbine is difficult due to complex flow pattern on different parts. The basic dimensions can be obtained from interpolation techniques and design trends but the main challenge is to model the hydrodynamic surface. The surface must be designed such that it would harvest energy in an efficient manner and the manufacturing of the surface is also economic and simple. For the design of Pelton turbine, the data from Kulekhani-I hydropower is taken. Pelton turbine is designed for the given head $(550 \mathrm{~m})$, flow rate $\left(6.05 \mathrm{~m}^{3} / \mathrm{sec}\right)$ and speed $(600 \mathrm{rpm})$. For basic dimensions, interpolation techniques and design trends are used. Number of buckets is calculated for maximum efficiency condition and found to be twenty. Nozzle and spear are selected based on hydraulic efficiency. Spear angle and nozzle angle of $70^{\circ}$ and $100^{\circ}$ respectively are selected. The bucket surface is designed with the help of second order B-Spline. Circular and Second order B-spline surfaces with different depths are analyzed using commercial CFD code. The second order B-Spline with depth 186.22 $\mathrm{mm}$ is found to be more effective in terms of force exerted by the jet among the given surfaces. Finally, Bucket surface is generated using non-uniform rational B-spline (NURBS) modeling after all the basic dimensions are determined. For verification, the design is compared with the design of commercial design software and the turbine in Kulekhani-I hydropower plant.
\end{abstract}

Keywords: Pelton, Design, CFD, Bucket Surface, Spline

\section{Introduction}

In Pelton turbines, energy is transferred into the shaft first through bucket. So, proper design of the bucket plays a vital role in increasing the overall efficiency of the turbine unit. The buckets are in the shape of double hemispherical which are divided by a sharp-edged ridge called splitter. If the bucket is exactly hemispherical, water would deflect through the angle of 180 degree and full momentum transfer takes place. But practically, the overall efficiency would decrease as the jet leaving the bucket strikes the back of the succeeding bucket. So, a cut-out is also done at the tip of the bucket to counter the effect of jet obstruction by the succeeding bucket [1]. Hence, the angular deflection of the jet is limited to about 165 degree to 170 degree in practice.

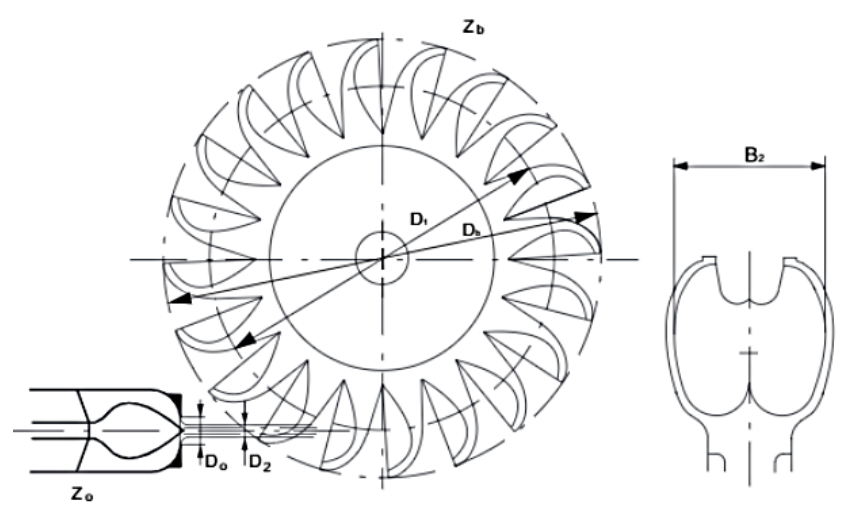

Figure 1: Schematic view of Pelton turbine

This paper is mainly focused on the design of Pelton bucket and runner considering flow rate, head and speed as design parameters. Bucket cross section is 
modeled using second order B-Spline and surface is generated using NURBS modeling technique. These design parameters are taken from a hydropower plant in Nepal, Kulekhani-I [2].

Table 1: Design input parameters

\begin{tabular}{|l|c|}
\hline Gross Head & $550 \mathrm{~m}$ \\
\hline Net head & $495 \mathrm{~m}$ \\
\hline Flow rate & $6.05 \mathrm{~m}^{3} / \mathrm{sec}$ \\
\hline Speed & $600 \mathrm{rpm}$ \\
\hline
\end{tabular}

The trend of bucket surface construction differs for every turbine manufactures and are usually kept a secret. Graphical methods are also used for the bucket surface generation [3]. Cubical spline algorithm and NURB surface are more common [4,5]. Bezier curve have been used for the surface generation with complex depth variation of bucket along the length [6]. The process is computationally expensive and these techniques don't encompass the effect of water film flow on the bucket surface. This study aims to fill the gap by analyzing the effect of depth of the bucket on the water film flow on the bucket surface.

For a simpler method of surface generation, CFD simulation has been performed for circular and second order B-spline varying the depth and the splitter angle keeping the exit angle and width of bucket considered constant. The exit of the bucket is considered to be semi elliptical. Finally, 3D NURB Surface is generated.

\section{B-Spline and NURBS Surface}

Bezier curves cannot be modified locally and the movement of the control points will affect the whole curve shape. So, in order to overcome the problems faced, the Bezier method has been used to generalize the B-spline method. . B-spline gives the freedom of modifying the curve in the local level without affecting the whole curve.

$\mathrm{A} \mathrm{d}^{\text {th }}$ degree B-spline curve can be defined as [7]:

$$
P(u)=\sum_{i=0}^{n+1} P_{i} N_{i}, d(u) \quad 0 \leq u \leq u_{\max }
$$

The Basis Function is recursively defined as [7]:

$N_{i, d}(u)=\frac{u-u_{i}}{u_{i+d-1}-u_{i}} N_{i, d-1}(u)+\frac{u_{i+d}-u}{u_{i+d}-u_{i+1}} N_{i+1, d-1}(u)$
Where,

$$
N_{i, 1}(u)= \begin{cases}1, & \text { if } u_{i} \leq u \leq u_{i+1} \\ 0, & \text { otherwise }\end{cases}
$$

where $P_{i}$ is the control points, for example, $P_{0}, \ldots, P_{n}$, $N_{(i, d)}$ are the dth-degree B-spline basis function, $\mathrm{U}$ is the knot vector with the range $U=\left\{0, \ldots, u_{\max }\right\}$

The NURBS surface is defined as [8]:

$$
\vec{r}(u, v)=\frac{\sum_{i=0}^{m} \sum_{j=0}^{n} w_{(i, j)} \vec{d}_{(i, j)} N_{(i, p)}(u) N_{(j, l)}(v)}{\sum_{i=0}^{m} \sum_{j=0}^{n} w_{(i, j)} N_{(i, p)}(u) N_{(j, l)}(v)}
$$

Where,

$\vec{d}_{(i, j)} \quad[i=0,1, \ldots, m ; j=0,1, \ldots, n]$ are control points.

$w_{(i, j)}$ are the weights corresponding to $\vec{d}_{(i, j)}$.

$p$ and $l$ are the degree of two parametric directions of a NURBS surface.

$N_{(i, p)}(u) \quad[i=0,1, \ldots, m]$ and $N_{(j, l)}(v)[j=0,1, \ldots, n]$ are canonical B-spline Basis functions and are defined as the Cox-de-Boor formula with the knot vectors,

$\vec{U}=\left[u_{0}, u_{1}, \ldots, u_{m+p+1}\right]$ and

$\vec{V}=\left[v_{0}, v_{1}, \ldots, v_{n+l+1}\right]$ as follows [8]:

$\left\{\begin{array}{l}N_{(i, 0)}= \begin{cases}1 & u_{i} \leq u<u_{i+1} \\ 0 & \text { otherwise }\end{cases} \\ N_{(i, p)}(u)=\frac{u-u_{i}}{u_{i+p}-u_{i}} N_{(i, p-1)}(u)+\frac{u_{i+p+1}-u}{u_{i+p+1}-u_{i+1}} N_{(i+1, p-1)}(u) \\ \text { if }, \frac{0}{0}=0\end{array}\right.$

\section{Design of Pelton Turbine}

\subsection{Selection of speed and size of runner}

The primary step in the design process of the Pelton turbine involves defining the number of jets (z) and the coefficient of the specific speed [9]. The speed number $(\Omega)$ is a dimensionless parameter given by

$$
\Omega=\omega \times \frac{Q^{\frac{1}{2}}}{(2 \times g \times H)^{\frac{3}{4}}}
$$

Where,

$\omega$ is angular velocity,

$\mathrm{Q}$ is volume flow,

$\mathrm{g}$ is acceleration due to gravity, and

$\mathrm{H}$ is gross head 
The speed number is calculated to be 0.154 . The calculations required further are made by using the number of jets $(z)=4$ as depicted by the graph. The size of the runner increases with the decrement in the number of nozzles. The turbine should not get too small in size because that makes the bucket radius small which increases the velocity of water in the buckets, and the amount of sand erosion. But the dimensions should not be too large to ease the transportation of the turbine to the site [10].

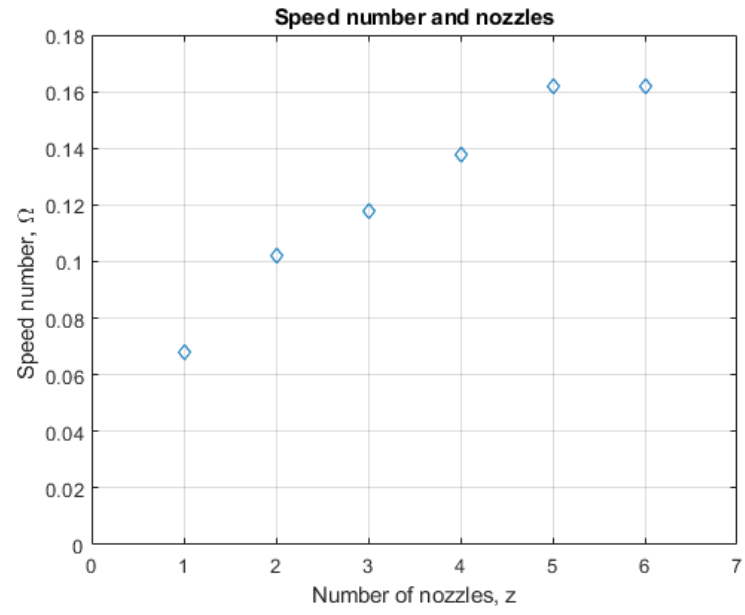

Figure 2: Variation of no of jets (z) with speed number $(\Omega)$

The design parameters are obtained from the relations generated from the obtained correlation between different turbines manufactured by Rain-power Turbines, Norway [10]. The calculated parameters are shown in Table 2.

Pelton turbine design is divided into four main sections regarding the design of parts as: Spear and Nozzle, Runner, Bucket and Jet.

Table 2: Various parameters calculated analytically

\begin{tabular}{|l|l|}
\hline Parameters & Value \\
\hline Volume flow, $\mathrm{Q}$ & $6.05 \mathrm{~m}^{3} / \mathrm{s}$ \\
\hline Density, $\rho$ & $1000 \mathrm{~kg} / \mathrm{m}^{3}$ \\
\hline Acceleration due to gravity, $\mathrm{g}$ & $9.81 \mathrm{~m} / \mathrm{s}^{2}$ \\
\hline Gross Head, $\mathrm{H}$ & $550 \mathrm{~m}$ \\
\hline Net head, $\mathrm{H}_{\text {net }}$ & $495 \mathrm{~m}$ \\
\hline Number of nozzles, $\mathrm{z}$ & 4 \\
\hline Jet diameter, $\mathrm{d}_{\mathrm{j}}$ & $0.1398258 \mathrm{~m}$ \\
\hline Bucket width, $\mathrm{B}$ & $0.4614253 \mathrm{~m}$ \\
\hline Bucket Length, $\mathrm{L}$ & $0.510 \mathrm{~m}$ \\
\hline Runner diameter, $\mathrm{D}$ & $1.5031278 \mathrm{~m}$ \\
\hline Rotational Speed, $\mathrm{N}$ & $600 \mathrm{rpm}$ \\
\hline Angular velocity, $\mathrm{w}$ & $62.8 \mathrm{rad} / \mathrm{s}$ \\
\hline Speed number, $\Omega$ & 0.154 \\
\hline
\end{tabular}

The values in Table 2 are calculated using the expressions as shown [10]:

$$
\text { Velocity of jet }(u)=\sqrt{2 \times g \times H_{n e t}}
$$

$$
\text { Diameter of jet }\left(d_{j}\right)=\sqrt{\frac{4 \times Q}{z \times \pi \times u}}
$$

The width of the bucket depends on the jet diameter and the number of jets, as follows:

$$
B= \begin{cases}3.1 \times d_{j} & \text { for } z=1 \\ 3.2 \times d_{j} & \text { for } z=2 \\ 3.3 \times d_{j} & \text { for } z=4 \text { to } 5\end{cases}
$$

The diameter of the runner is given by:

$$
D=d_{j} \times(0.005 H+8)
$$

The length of Bucket is calculated as [11]:

$$
\text { Length of bucket }(L)=0.34 \times D
$$

\subsection{Spear and Nozzle}

The analysis of pair of nozzle and spear of different dimensions has been studied experimentally and numerically $[12,13]$. Commercial nozzle spear with spear and nozzles angles 55 degree and 80 degree respectively are found to have $0.4 \%$ more hydraulic losses than in a new design with spear and nozzle angles 70 degree and 110 degree respectively. One more with angles (90/150) is analyzed but (70/110) is found to be most efficient. This could be due to the differences in the 3D flow structure details like secondary flows, which affects both the runner and the nozzle performance and therefore, the hydraulic efficiency [12].

Spear and nozzle with angles (70/110) have been selected for the design. Figure 3 shows the nozzle angle and spear angle. 


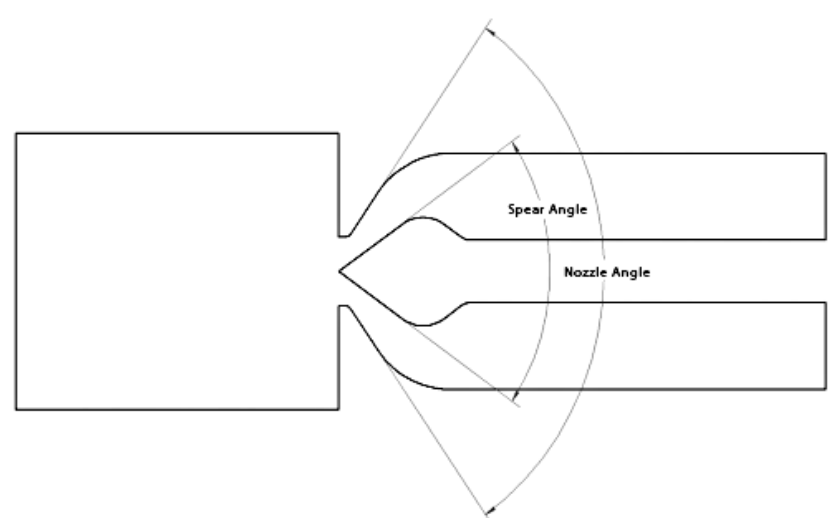

Figure 3: Image showing spear angle and nozzle angle

\subsection{Number of Buckets}

Runner diameter has been calculated using the relations developed [10]. Another parameter to be considered while designing the runner is the number of buckets. A relation is developed from the correlation of the turbines manufactured by Rain power Turbines, Norway. Another relation is developed for achieving maximum possible efficiency. To validate the formula, performance test is carried out by using runners with different numbers of buckets on a Pico-scale Pelton turbine. The formula for the bucket selection, with the confirmation that the calculated number of buckets maximizes the efficiency of the Pelton turbine is validated by the results of the test. The number of bucket is calculated to be 20 [14]. The calculation for the number of buckets is as shown below [14]:

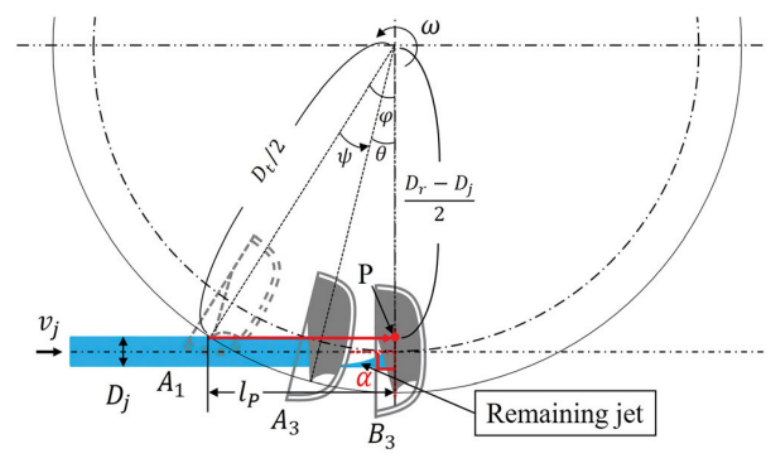

Figure 4: Image for calculation of no of buckets [14]

The angle between bucket $\mathrm{A}$ and the vertical line is represented by $\varphi$. The bucket pitch angle is indicated by $\theta$, the rotation angle of the bucket is indicated by $\Psi$. $\varphi$ is expressed as:

$$
\varphi=\arccos \left(\frac{D_{r}-D_{j}}{D_{t}}\right)
$$

Speed ratio(x) is defined as:

$$
x=\frac{V_{r}}{V_{j}}=\frac{\omega D_{r}}{2 V_{j}}
$$

Then,

$$
\theta=\varphi-\left(\frac{D_{t}}{D_{r}}\right) x \sin \varphi
$$

Finally,

$$
\text { No. of buckets }=\frac{2 \pi}{\theta}
$$

There is no novel approach for the selection of no of buckets. The use of this method for the selection can help to determine the no of bucket so that maximum energy can be harvested as no part of jet gets wasted.

\subsection{Bucket}

Dimensions such as bucket width and length have been calculated as shown in Table 2. Still some important parameters such as split angle, exit angle, cut-out and depth are missing. Bucket parameters such as width, depth, splitter angle, exit angle, shape and the cut-out govern the geometry of the bucket [15].

The effect of the splitter angle has been found to be negligible [4], but usually kept above 20 degree to prevent from erosion [9].Split angle of measure 27.5 degree and exit angle of 15 degree is selected. No enough literature is found for determination of depth of bucket so CFD simulations have been performed to determine the depth of bucket using a commercial CFD code.

Cut-out is not present in the patent Pelton bucket. However, bucket with a cut-out can be seen in recent studies [3]. It ensures a continuous torque generation and a smoother flow [15]. The performances of bucket on varying the shape of cut-out have been studied [16]. So, a circular cut-out of diameter $10 \%$ greater than the diameter of jet has been made on the bucket. The Coanda effect in the cut-out area that enables the flow to cling to the surface against a positive pressure gradient has been described [17]. To prevent cavitation, sharp angle is created on the back side of the cutout [18]. 


\subsection{Water jet}

An ideal jet assumed to be straight with a constant area, and to be directed along the axis of the injector would have a uniform velocity across its cross-section, a constant velocity along its axis, and no transverse velocity components [19]. The secondary flows generated during the flow may deteriorate the quality of jet by increasing the radial velocity and offsetting the core of the jet away from the axis of spear tip.

The distance between the nozzle and the runner can also affect the efficiency of the turbine. So, an optimum separation of nozzle and the runner is required. As the distance between the jet and the bucket is increased, the radial flow increase and the axial flow decrease that result in the spreading of jet [20]. Near from the nozzle the jet is not properly developed which is still accelerating, so the impact force would not be enough to generate energy in an efficient manner.

With the introduction of efficient CFD tools, the design of reaction turbines like Francis, Bulb, or Kaplan turbines has significantly improved over the last decade. However, it has always been more difficult to model impulse turbines because of complex flow pattern in bucket and jet [17].

\section{Simulation for determination of bucket depth}

Cross sections with circular arc and Second order BSpline has been studied for the study of depth. Twodimensional simulation is performed in a commercial CFD code for the determination of optimum bucket depth. Eight different depth for Circular arc and eight different depths for the second order B-Spline have been analyzed.

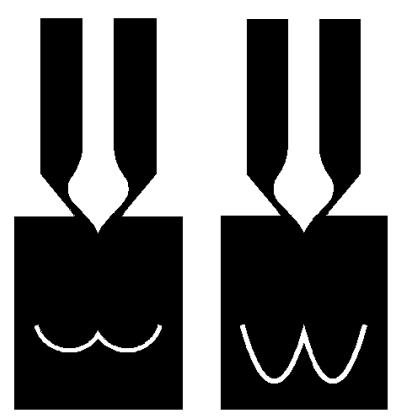

Figure 5: Buckets with circular arc (left) and B-spline type (right) cross-section

\subsection{Mesh independency}

The computational domain is discretized. The generated mesh is quad mesh. The grid independency test is performed in which the force on bucket remained almost constant on increasing the number of nodes further than 260,000. So, 260,000 nodes are sufficient to carry out the simulation within the tolerance of $0.01 \%$. Inflation is created on the wall of the bucket and the walls of spear to capture the boundary layer.

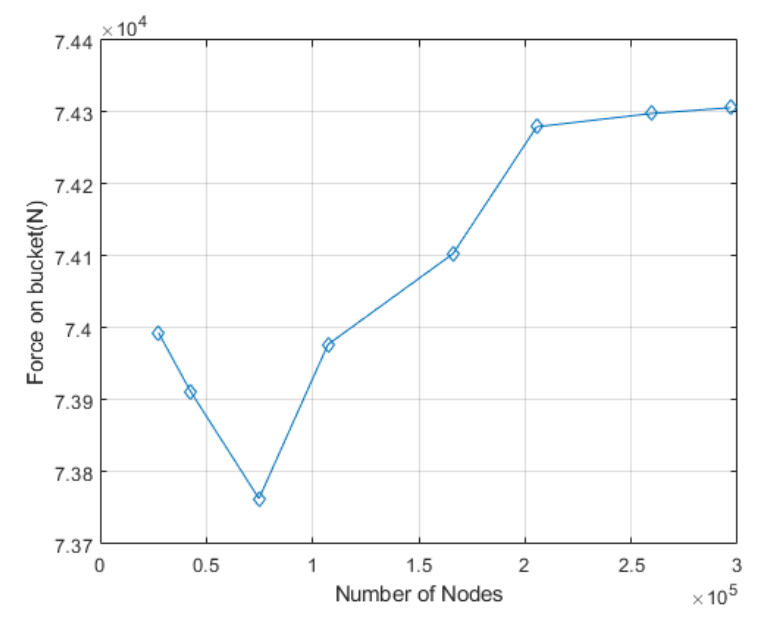

Figure 6: Mesh independency

\subsection{Defining simulation parameters}

The realizable $k-\varepsilon$ model has been used for the flow study and the study of dynamics of Pelton turbine [21]. The realizable $k-\varepsilon$ model is based on the dynamic equation of the mean-square vorticity fluctuation at large turbulent Reynolds number [22]. Since it's a dual phase problem, VOF (Volume of fluid) model has been selected [12, 21, 23].

Table 3: Simulation Parameters

\begin{tabular}{|l|l|}
\hline $\begin{array}{l}\text { Time } \\
\text { dependence }\end{array}$ & Steady state \\
\hline Model & $\begin{array}{l}\text { 1. Multiphase: volume of fluid (VOF) } \\
\text { 2. Viscous: Realizable } k-\varepsilon\end{array}$ \\
\hline Phases & $\begin{array}{l}\text { 1. Air } \\
\text { 2. Water-liquid }\end{array}$ \\
\hline Inlet 1 & $\begin{array}{l}\text { Mass flow inlet }(\mathrm{kg} / \mathrm{s}): \\
\text { Water }(754.7 \mathrm{~kg} / \mathrm{s})\end{array}$ \\
\hline Inlet 2 & $\begin{array}{l}\text { Mass flow inlet }(\mathrm{kg} / \mathrm{s}): \\
\text { Water }(754.7 \mathrm{~kg} / \mathrm{s})\end{array}$ \\
\hline Outlet & Pressure Outlet \\
\hline
\end{tabular}

The simulation is performed on the 16 different geometries (Circular arc and second order B-Spline). 
The force exerted by the jet on the bucket is studied and it varies as shown in Figure 8 and Figure 9.

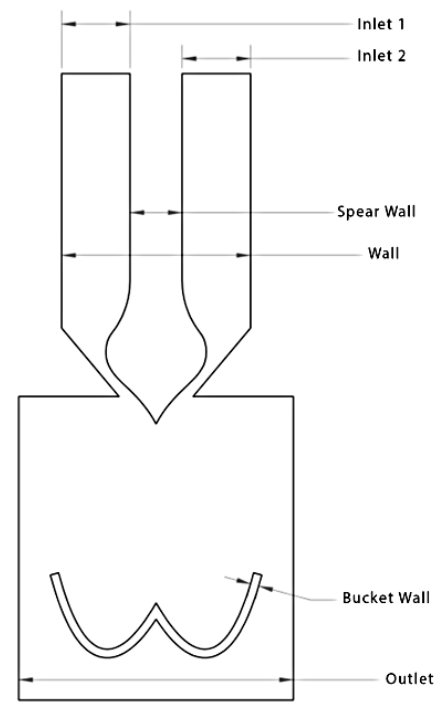

Figure 7: Boundary Conditions

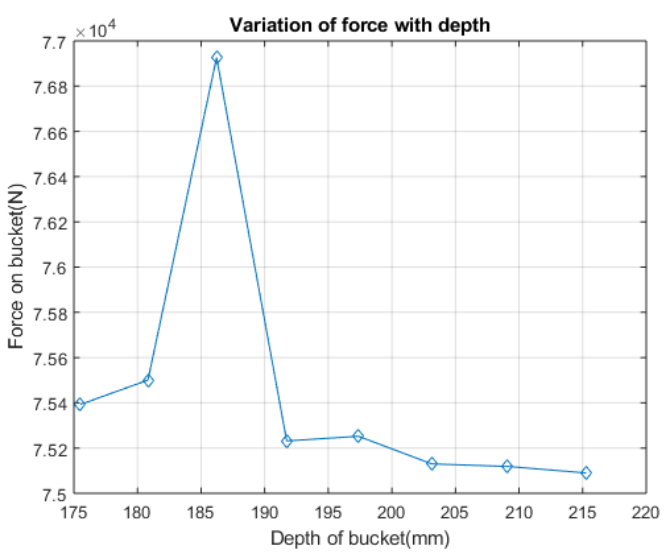

Figure 8: Force vs Depth of 2nd Order B-spline type of 2D cross-section

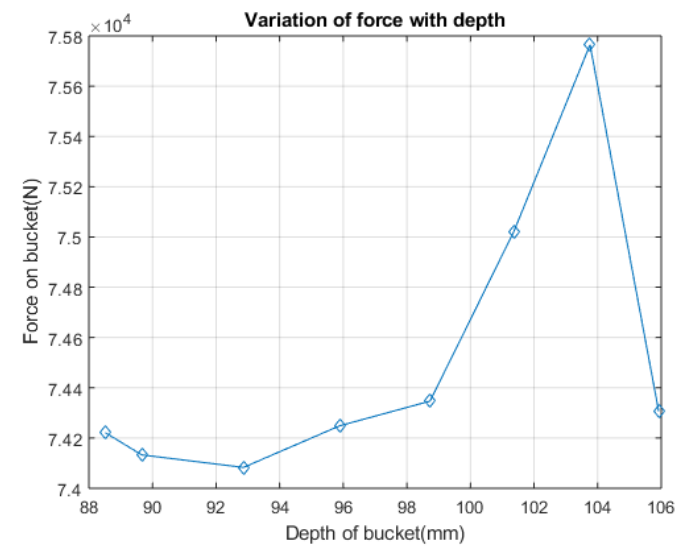

Figure 9: Force vs. Depth of Circular Arc type of 2D cross-section
It can be seen that the jet exerts maximum force for a given depth for both types of cross section. Force increases gradually and after crossing an optimum value, it starts decreasing. For maximum energy transfer, maximum force on the bucket is desired. For the 2nd degree B-spline type of bucket, maximum force of $76926.148 \mathrm{~N}$ is obtained at the depth of $186.22 \mathrm{~mm}$ and for the Circular arc type of bucket, maximum force of $75764.663 \mathrm{~N}$ is obtained at the depth of $103.76 \mathrm{~mm}$. The force is more for B-Spline cross section, so it is considered optimum for our design.

The variation of force can be visualized by observing the water volume fraction for flow on those cross sections. The deflection of jet is more for the B-spline cross section than that of circular arc as shown in Figure 10 and Figure 11.

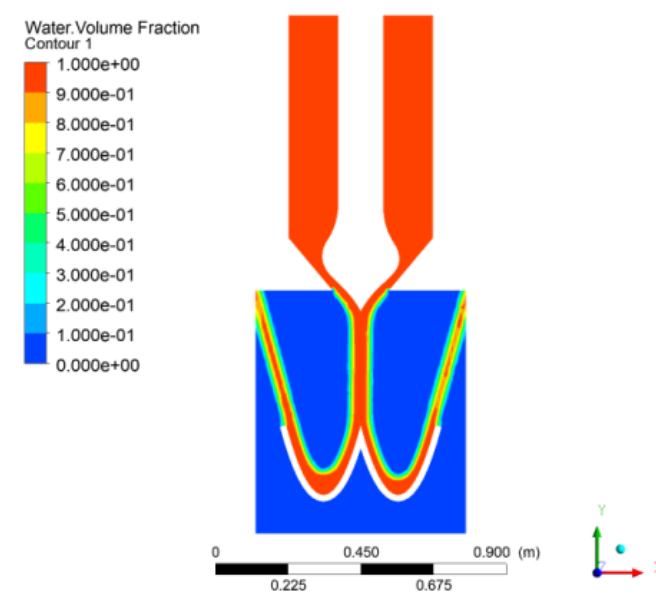

Figure 10: Water volume fraction of circular arc type cross-section

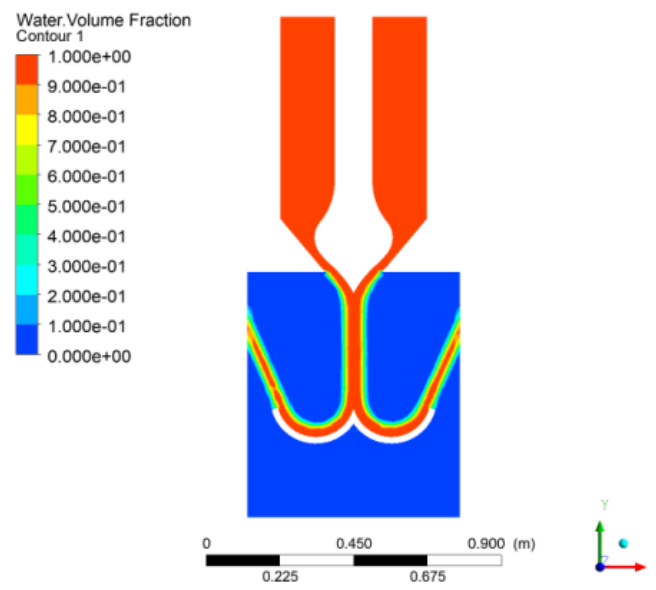

Figure 11: Water volume fraction of 2nd order B-spline type cross-section 


\subsection{Simulation convergence}

Initial value can highly affect the rate of convergence, so before running the simulation, to calculate the force, another simulation is run with predicted value and is run until the RMS residual drop to e-5. The velocity, pressure, $k$ and $\varepsilon$ obtained from the simulation are used as initial value for the calculation of force on different buckets. Coupled solver was used with pseudo transient formulation. The couple solver was coupled with volume fraction for correction in value of continuity and momentum as calculated by coupled solver.

\section{3D model of bucket}

The bucket is considered to be semi-elliptical. Optimum cross section is obtained from the simulation. Using those curves, NURBS surface is generated as shown in Figure 12.

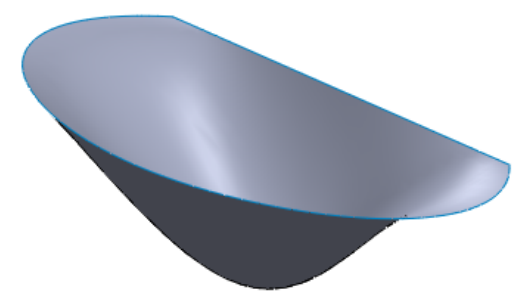

Figure 12: Pelton bucket surface

A circular cut-out with diameter $10 \%$ more than the jet diameter is made for the smooth transition of bucket and jet. The generated bucket model is as shown in Figure 13 and Figure 14.

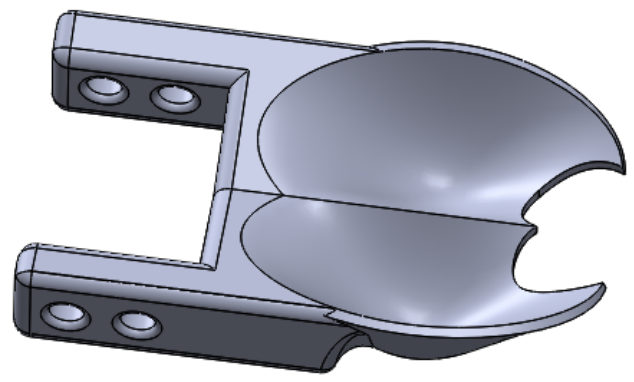

Figure 13: A view of three Dimensional model of the Pelton bucket

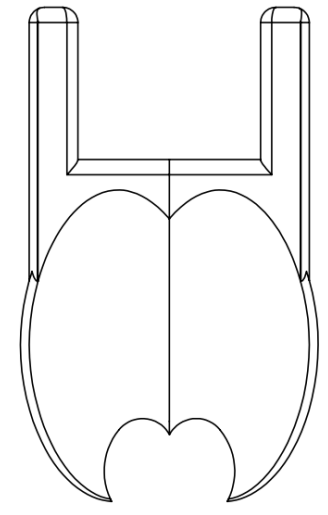

Figure 14: Drawing of top view of modeled Pelton bucket

\section{Verification of design}

Commercial software has been used for the validation of analytically calculated parameters [24,25]. A computerized library of a python program has been developed by measuring different models of Pelton turbines, which is used to design industrial Pelton turbines [24]. Commercial Pelton turbine design software is used for the validation of calculated parameters. Further, the input parameters are from the Kulekhani - I hydropower so the design is also compared with the turbine in Kulekhani-I. The comparison between the designed parameters, parameters from commercial software and the parameters from Kulekhani-I hydropower is shown in Table 4.

Table 4: Design verification

\begin{tabular}{|l|c|c|c|}
\hline Index & Designed & $\begin{array}{c}\text { Commercial } \\
\text { Software }\end{array}$ & $\begin{array}{c}\text { Kulekhani-I } \\
\text { Hydropower }\end{array}$ \\
\hline $\begin{array}{l}\text { Runner pitch } \\
\text { diameter (D) }\end{array}$ & $1503 \mathrm{~mm}$ & $1585 \mathrm{~mm}$ & $1562 \mathrm{~mm}$ \\
\hline $\begin{array}{l}\text { Outer diameter } \\
\text { of bucket }\end{array}$ & $2013 \mathrm{~mm}$ & $2090 \mathrm{~mm}$ & $2045 \mathrm{~mm}$ \\
\hline $\begin{array}{l}\text { Bucket } \\
\text { length (L) }\end{array}$ & $510 \mathrm{~mm}$ & $505 \mathrm{~mm}$ & $407.7 \mathrm{~mm}$ \\
\hline $\begin{array}{l}\text { Bucket } \\
\text { width (B) }\end{array}$ & $461.4 \mathrm{~mm}$ & $505 \mathrm{~mm}$ & $490 \mathrm{~mm}$ \\
\hline D/B & 3.257 & 3.138 & 3.254 \\
\hline $\begin{array}{l}\text { Depth of } \\
\text { bucket (d) }\end{array}$ & $186.22 \mathrm{~mm}$ & N/A & $147 \mathrm{~mm}$ \\
\hline No. of buckets & 20 & N/A & 19 \\
\hline
\end{tabular}

\section{Discussion}

The variation of force due to depth of bucket is explained with the help of obtained velocity contours. 


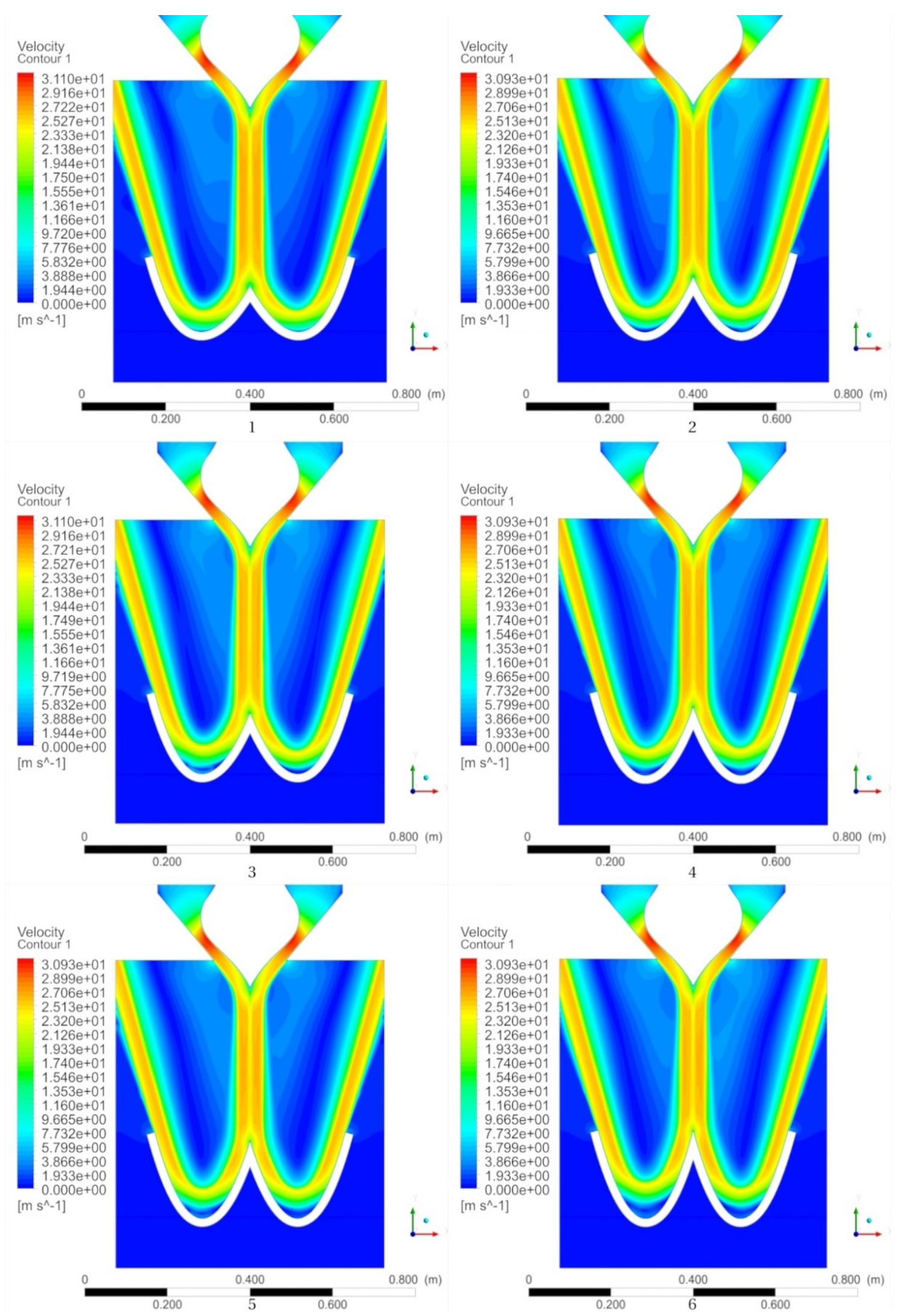

Figure 15: Velocity contour of different B-spline cross-section buckets with depth

(1. $180.82 \mathrm{~mm}, 2.191 .73 \mathrm{~mm}, 3.197 .36 \mathrm{~mm}, 4.203 .14 \mathrm{~mm}, 5.209 .10 \mathrm{~mm}, 6.215 .15 \mathrm{~mm})$ 
If we observe the velocity near the maximum depth position, after crossing the depth of $186.22 \mathrm{~mm}$, stagnation layer was seen dominant at those areas. The water striking at the bucket also loses its energy in the form of eddies.

The flow separation that may occur in penstock deteriorates the quality of jet which ultimately affects the efficiency of the turbine [19]. So, flow separation must be prevented to enhance the efficiency of runner. Furthermore, the mechanical strength of different parts should be studied for long run of the turbine. We recommend the study of mechanical stress generated on the bucket surface and different couplings for a mechanically robust design.

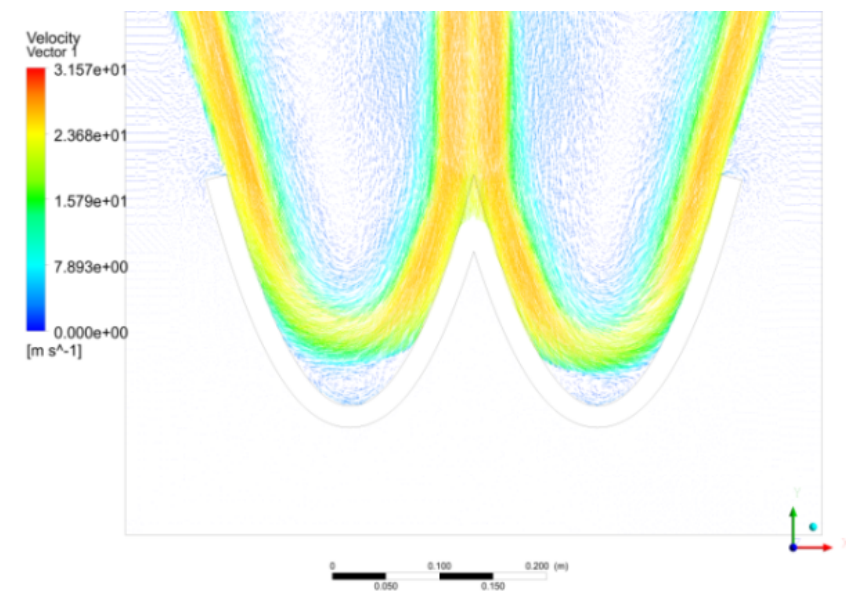

Figure 16: Eddies formation on B- Spline bucket with depth $215.26 \mathrm{~mm}$

\section{Conclusion}

Pelton turbine is designed as per the given parameters (flow rate, head and speed of runner). Some components like penstock, generator, coupling etc. has not been considered. The use of B-spline and NURBS for the design of Pelton bucket can make the design process efficient. The Computational Fluid Dynamics analysis of flow in Pelton turbine and calculation of force on different surfaces helps to conclude that, the force on the bucket increases with the increase of depth up to a certain limit and then the force decreases. For same depth of bucket, the force on B-Spline driven NURBS surface have more force exerted than the conventional circular bucket profile. The flow analysis on the bucket also shows that with the increase in depth of the bucket after the limit, the vortices become more dominant. This might be the reason for the decrease of force on bucket after crossing a certain depth. The forces for B-Spline cross-sections of depth $180.82 \mathrm{~mm}, 186.22 \mathrm{~mm}, 191.73$ $\mathrm{mm}, 197.36 \mathrm{~mm}, 203.14 \mathrm{~mm}, 209.10 \mathrm{~mm}$ and 215.15 $\mathrm{mm}$ are $75.5 \mathrm{kN}, 76.92 \mathrm{kN}, 75.23 \mathrm{kN}, 75.25 \mathrm{kN}, 75.12$ $\mathrm{kN}, 75.11 \mathrm{kN}$ and $75.09 \mathrm{kN}$ respectively. The maximum force was achieved in the B-Spline driven NURBS with depth $186.22 \mathrm{~mm}$.

\section{References}

[1] A. Joaquim and L. Jorge, "Energy harvesting from hydroelectric systems for remote sensors.".

[2] Nepal Electricity Authority (NEA), "Generation Directorate," NEA, Kathmandu, Nepal, 2019.

[3] M. Hana, "Improvements of a graphical method for calculation of flow on a pelton bucket.," 1996.

[4] A. Židonis, A. Panagiotopoulos, G. A. Aggidis, J. S. Anagnostopoulos and D. E. Papantonis, "Parametric optimisation of two Pelton turbine runner designs using CFD," Journal of Hydrodynamics, vol. 27, no. 3, pp. 403-412, 2015.

[5] J. S. Anagnostopoulos and D. E. Papantonis, "A fast lagrangian simulation method for flow analysis and runner design in pelton turbine," Journal of hydrodynamics, vol. 24, no. 6, pp. 930-941, 2012.

[6] W. S. Bjørn, "Experimental methods and design of a pelton bucket," 2016.

[7] H. Haron, A. Rehman, D. I. S. Adi, S. P. Lim and T. Saba, "Parameterization Method on B-Spline Curve," 2012.

[8] Y. Zhao, X. W. Shi and L. Xu, "Modeling of Nurbs Surfaces used for the calculation of RCs.," 2008.

[9] T. L. Bovet, "Turbine Pelton: Extrait du cours de machines hydrauliques de," 1952.

[10] L. S. Drange, "Dimensioning of Kirne Power Plant in Nepal," NTNU, 2009.

[11] J. Thake, Micro-Hydro Pelton Turbine Manual: Design Manufacture and Installation for Small-Scale, 2001.

[12] Z. Audrius, "Experimental investigation and analysis of the spear valve design on the performance of Pelton turbines: Three case studies," 2017.

[13] D. Benjon, "Numerical investigation of the spear valve configuration on the performance of Pelton and Turgo turbine injectors and runners".

[14] J. W. Kim, I. C. Jo, J. H. Park, Y. Shin and J. T. Chung, "Theoretical method of selecting number of buckets for the design and verification of a Pelton turbine.". 
[15] S. Bhattarai, P. Vichare, K. Dahal, M. . A. Al and A.G. Olabi , "Novel trends in modelling techniques of Pelton Turbine bucket for increased renewable energy production.”.

[16] Budiarso, Warjito, A. D, S. P. Nesen and V. Hans, "Cutout Types Analysis on Pico Hydro Pelton Turbine".

[17] P. Alexandre, "Hydrodynamics of the free surface flow in pelton turbine buckets.".

[18] A. A. Fulton, "Present tendencies in water turbine machinery".

[19] Z. Zhang and M. Casey, "Experimental studies of the jet of a Pelton turbine," 2007.

[20] V. Gupta, R. Khare and V. P., ,'Effect of jet length on the performance of pelton turbine: distance between nozzle exit and runner.".
[21] Y. X. Xiao, T. Cui, Z. W. Wang and Z. G. Yan, "Numerical simulation of unsteady free surface flow and dynamic performance for a Pelton turbine".

[22] T. H. Shih, "A new k-epsilon eddy viscosity Model for high Reynolds number turbulent flows: Model development and validation.," 1994.

[23] M. Choi, Y. J. Jung and Y. Shin, "Unsteady flow simulations of Pelton turbine at different rotational speeds.”.

[24] A. Bostan, N. Dorian and F. Periș-Bendu, "The Hill Chart Calculation for Pelton Runner Models using the HydroHillChart - Pelton Module Software".

[25] S. Sabu, N. J. George, A. Tom and A. Alex, "Design and Modelling of a Pelton Wheel Bucket Theoretical Validation And Software Comparison," 2014. 